\title{
Serum Cellular Apoptosis Susceptibility Protein Is a Potential Prognostic Marker for Metastatic Colorectal Cancer
}

\author{
Chin-Shaw Stella Tsai, ${ }^{*}$ Hung-Chang Chen, ${ }^{\dagger}$ \\ Jai-Nien Tung, ${ }^{\ddagger}$ Shung-Sheng Tsou, ${ }^{\ddagger}$ \\ Tang-Yi Tsao, ${ }^{\S}$ Ching-Fong Liao, ${ }^{\pi}$ \\ Ying-Chun Chen, "Chi-Yuan Yeh," \\ Kun-Tu Yeh, ${ }^{*{ }^{+\dagger}}$ and Ming-Chung Jiang ${ }^{\star}$ \\ From the Departments of Medical Research," Surgery, ${ }^{\ddagger}$ Pathology, \\ and Radiation Oncology," Tungs' Taichung MetroHarbor \\ Hospital, Taichung; the Division of Colorectal Surgery, ${ }^{\dagger}$ and \\ Department of Pathology,** Changhua Christian Hospital, \\ Changhua; the Institute of Cellular and Organismic Biology, ${ }^{\text {Tा }}$ \\ Academia Sinica, Taipei; and the Institute of Clinical Research, \\ Kaobsiung Medical University, Kaobsiung, Taiwan
}

Colorectal cancer has high rates of recurrence and metastasis. Many patients with similar histopathological features show significantly different clinical outcomes, and these differences are primarily related to metastases undetected by current diagnostic methods. There is no useful serological marker for metastatic disease. We investigated the cellular apoptosis susceptibility (CSE1L/CAS) protein in comparison with carcinoembryonic antigen (CEA) as a marker for metastatic colorectal cancer. Using serum from 103 patients with stage I, II, III, and IV disease, CSE1L was detected in $36.0 \%$ ( 9 of 25 ), $57.7 \%$ (15 of 26 ), $71.4 \%$ (30 of 42), and 88.9\% (8 of 9) of patients, respectively; a pathological CEA level was found in $16.0 \%$ ( 4 of 25 ), $42.3 \%$ (11 of 26$), 47.6 \%$ (20 of 42$)$, and $77.8 \%$ (7 of 9) of patients, respectively; a combined CSE1L/CEA assay was detected in $48.0 \%$ (12 of 25$), 65.4 \%$ (17 of 26$)$, $88.1 \%$ ( 37 of 42 ), and $100 \%$ ( 9 of 9 ) of patients, respectively. Lymphatic metastasis is an important predictor of poor prognosis and crucial for determination of therapeutic strategy. Serum CSE1L was detected in $74.5 \%$ (38 of 51) of patients with lymph node metastasis, whereas a pathological CEA level was found in only $52.9 \%$ ( 27 of 51 ) of the same patients $(P<0.001)$; the combined CSE1L/CEA assay increased sensitivity to $90.2 \%$ (46 of 51). Animal experiments showed CSE1L reduction in B16-F10 melanoma cells correlated with decreased metasta- sis to the colorectal tract in $\mathrm{C} 57 \mathrm{BL} / 6$ mice. These results indicate that assay of serum CSE1L may facilitate diagnosis of colorectal cancer lymphatic metastases; furthermore, CSE1L is a possible therapeutic target. (Am J Pathol 2010, 176:1619-1628; DOI: 10.2353/ajpath.2010.090467)

Colorectal cancer is one of the most common causes of cancer-related deaths worldwide, and patients are at risk for both recurrent cancer and metachronous neoplasms in the colon or rectum after surgical removal of the original lesions. Prognosis of colorectal cancer is stage- and grade-dependent, and many tumors with similar histopathological features show significantly different clinical outcomes. Approximately $60 \%$ of patients who undergo curative resection will experience local recurrence or distant metastases. ${ }^{1,2}$ In $85 \%$ of patients, relapse is diagnosed within the first 2.5 years after surgery. ${ }^{3}$ Up to $30 \%$ of patients assessed by traditional histopathology methods with stage II disease (lymphatic metastasisnegative disease) experience recurrence of their cancer. ${ }^{4}$ Moreover, although patients with stage I colorectal cancer usually have a good prognosis, some die of local or distant recurrence after curative resection. ${ }^{5,6}$ These deaths are primarily related to metastases that were not detectable by current pathological or clinical evaluations.

Lymph node metastasis is an important prognostic indicator for disease progression and is crucial for determination of therapeutic strategy in treatment of colorectal cancer. Nevertheless, there is currently no useful serological marker for metastatic colorectal cancer, especially lymphatic metastasis. ${ }^{7-13}$ Carcinoembryonic anti-

Supported by a grant (TTMHH-97R0017) from Tungs' Taichung MetroHarbor Hospital, Taichung, Taiwan.

Accepted for publication December 11, 2009.

Address reprint requests to Ming-Chung Jiang, Ph.D., Department of Medical Research, Tungs' Taichung MetroHarbor Hospital, Number 699, Section 1, Chungchi Rd, Wuchi, Taichung County 435, Taiwan or Kun-Tu Yeh, M.D., Department of Pathology, Changhua Christian Hospital, Number 135, Nan-Hsiao. St., Changhua 500, Taiwan. E-mail: jiangmcedu@ yahoo.com.tw or 10159@cch.org.tw. 
gen (CEA) is the marker most frequently evaluated as a predictor of prognosis for patients with colorectal cancer; Thomson $\mathrm{et}^{\mathrm{al}}{ }^{14}$ reported that CEA was detectable in the serum of $97 \%$ of patients with colorectal cancer. However, high serum levels of CEA appear to be clinically relevant for a much smaller population: patients with advanced disease including extensive metastases, especially of the liver. ${ }^{15}$ Other authors have reported that the level of serum CEA does not correlate with the presence of metastasis at all and there are high frequencies of false-positive and false-negative results when CEA level is evaluated as part of the workup for possible metastatic disease. ${ }^{16,17}$ Hence, the major current utility of CEA in colorectal carcinoma is monitoring for recurrence after surgical resection. ${ }^{18}$

The cellular apoptosis susceptibility (CSE1L/CAS) protein is the human homologue of the yeast chromosome segregation gene product, CSE $1 .{ }^{19} \mathrm{CSE} 1 \mathrm{~L}$ (or CAS) can regulate apoptosis induced by interferon- $\gamma,{ }^{20}$ chemotherapeutic drugs, ${ }^{21,22}$ Pseudomonas exotoxin, diphtheria toxin, and tumor necrosis factor. ${ }^{19}$ Expression of CSE1L protein in cancer tissue has a positive correlation with high disease stage, high tumor grade, and worse clinical outcome. ${ }^{23}$ Tumors with high metastatic potential secrete various proteinases that degrade extracellular matrix and help cells invade adjacent tissue and then metastasize to other organs. ${ }^{24}$ Cancer cells that develop enhanced secretion of extracellular matrix-degradation proteinases may increase their biological aggressiveness. ${ }^{25}$ Matrix metalloproteinase-2 (MMP-2) is an extracellular matrixdegradation proteinase secreted from invasive cancer cells that enhances metastasis of many cancers, including colorectal cancer. ${ }^{26}$ Studies showed that CSE1L regulates translocation and secretion of MMP-2 from colorectal cancer cells. ${ }^{27,28}$ CSE1L is located on chromosome 20q13, a region that frequently has amplifications correlating with greater biological aggression of colorectal carcinomas. ${ }^{29}$ A comparative genomic hybridization study showed an association between chromosomal 20q11.2-20q13.2 amplification and enhanced lymphatic and liver metastasis in patients with colorectal cancer. ${ }^{30}$ Our recent study also revealed that CSE1L is a secretory protein and that there is a higher prevalence of secretory CSE1L in the sera of patients with metastatic cancer. ${ }^{31}$ Therefore, CSE1L may play an important role in regulating metastasis of colorectal cancer.

As noted previously, many patients with similar histopathological features show significantly different clinical outcomes, and these differences are frequently related to undetected metastases. Because there is no current reliable marker for metastatic colorectal cancer, we studied the value of serum CSE1L and CEA in predicting metastatic colorectal cancer in the clinical setting. Because CSE1L may play an important role in mediating metastasis of colorectal cancer, experimental metastasis assay was also performed to study the effect of CSE1L reduction on colorectal cancer metastasis. We report herein that the presence of serum CSE1L has a close relationship with lymph node or distant metastasis (eg, stage III or stage IV disease) and that a combined CSE1L/CEA assay further increased the sensitivity of metastatic colorectal cancer assay. Stage I and stage II colorectal cancers are lymphatic metastasis-negative as assessed by traditional histopathology. However, recurrence occurs in a significant fraction of patients, and CSE1L is positive in the serum of many of these patients. Thus, CSE1L may be a marker that facilitates diagnosis of metastatic colorectal cancer. Moreover, our animal metastasis studies suggest that CSE1L may be a target for antimetastasis therapy of colorectal cancer.

\section{Materials and Methods}

\section{Antibodies}

Antibodies were anti-CSE1L clone 3D8 (Abnova, Taipei, Taiwan), anti-CSE1L (C-20) and anti-MMP-2 (H-76; Santa Cruz Biotechnology, Santa Cruz, CA), anti-CSE1L (AP1935a; Abgent, San Diego, CA), anti- $\beta$-actin (Ab-5; Neomarker, Fremont, CA), and goat anti-mouse IgG secondary antibodies coupled to Alexa Fluor 568 (Molecular Probes, Eugene, OR).

\section{Cells, Vectors, and DNA Transfections}

HT-29 colorectal cancer cells and B16-F10 melanoma cells were obtained from the American Type Culture Collection (Manassas, VA). Both cell lines were cultured in Dulbecco's modified Eagle's medium supplemented with $10 \%$ heat-inactivated fetal bovine serum, 100 units $/ \mathrm{ml}$ of penicillin, $100 \mu \mathrm{g} / \mathrm{ml}$ of streptomycin, and $2 \mathrm{mmol} / \mathrm{L}$ of glutamate at $37^{\circ} \mathrm{C}$ under a humidified $5 \% \mathrm{CO}_{2}$ atmosphere. ${ }^{32}$ The pcDNA-CSE1L vector ${ }^{28}$ was cut with Apal and HindlII, and the 516-bp CSE1L fragment (bp 1 to 516) was cloned into pcDNA3.1 vector (Invitrogen, Carlsbad, CA) in an antisense direction to obtain pcDNA-antiCSE1L vector. The identity of the DNA sequences was determined by DNA sequencing. B16-F10 cells were transfected with vectors by using the Lipofectamine plus reagent (Invitrogen). Transfected cells were selected with G418 for 3 weeks. Multiple drug-resistant colonies $(>100)$ were pooled together and amplified in mass culture. The transfected cells were maintained in media containing $200 \mu \mathrm{g} / \mathrm{ml}$ of G418; for the experiments, cells were cultured in medium without G418.

\section{Immunofluorescence}

Cells grown on coverslips $(12 \times 12 \mathrm{~mm})$ were cytospun at $1000 \mathrm{rpm}$ for 10 minutes. Cells were washed with PBS, fixed with $4 \%$ paraformaldehyde, permeabilized with $0.1 \%$ Triton $X-100$ in $4 \%$ paraformaldehyde, and blocked with PBS-containing $0.1 \%$ bovine serum albumin and $0.5 \%$ Tween 20. Cells were incubated with the clone 24 anti-CSE1L antibodies, washed with PBS, and incubated with goat anti-mouse $\lg G$ secondary antibodies coupled to Alexa Fluor 568. Coverslips were examined with a Zeiss Axiovert 200M inverted fluorescence microscope (Carl Zeiss, Jena, Germany). 


\section{Conditioned Medium}

Cells were grown to subconfluence, washed with PBS, and changed to medium without fetal bovine serum. After incubation for 48 hours, the conditioned medium was collected. To remove possible suspended cells or cell debris, medium was centrifuged at 10,000 rpm for 10 minutes, after which supernatant was harvested. The conditioned medium was used as the control in immunoblotting.

\section{Immunoblotting}

Cells were harvested with a rubber policeman, washed with ice-cold PBS, and lysed in ice-cold radioimmunoprecipitation assay buffer $(25 \mathrm{mmol} / \mathrm{L}$ of Tris-HC1, pH 7.2, $0.1 \%$ SDS, $0.1 \%$ Triton $\mathrm{X}-100,1 \%$ sodium deoxycholate, $150 \mathrm{mmol} / \mathrm{L}$ of $\mathrm{NaC} 1,1 \mathrm{mmol} / \mathrm{L}$ of EDTA, $1 \mathrm{mmol} / \mathrm{L}$ of sodium orthovanadate, $1 \mathrm{mmol} / \mathrm{L}$ of phenylmethanesulfonyl fluoride, $10 \mu \mathrm{g} / \mathrm{ml}$ of aporotinin, and $5 \mu \mathrm{g} / \mathrm{ml}$ of leupeptin). Samples were resolved with 8\% SDS-polyacrylamide gel electrophoresis. Proteins were transferred to nitrocellulose membranes (Amersham Pharmacia, Buckinghamshire, UK), and immunoblotting was performed by using an ECL Plus Western Blotting Detection System (GE Health care, Little Chalfont, Buckinghamshire, UK) according to the manufacturer's instructions.

\section{Immunohistochemistry}

Immunohistochemistry was performed on 6- $\mu \mathrm{m}$ formalinfixed/paraffin-embedded cancer tissue sections by using a 50-fold dilution of clone 3D8 anti-CSE1L antibodies or H-76 anti-MMP-2 antibodies. Immunohistochemical detection was performed by using a labeled streptavidinbiotin method with the Histostain kit according to the manufacturer's instructions (Zymed, San Francisco, CA). Sections were developed with diaminobenzidine, washed with distilled water, and counterstained with Mayer's hematoxylin.

\section{Patients and Serum Samples}

Control donor serum samples were obtained from 47 healthy individuals (mean age, $58.5 \pm 11.6$ years; range, 17 to 79 years). Serum samples from patients with colorectal cancer who had not yet been treated were obtained from 103 consecutive patients who had recently been given a diagnosis and who were admitted to Changhua Christian Hospital, Taiwan. All participants had the study explained to them and gave informed consent by using institutional review board-approved guidelines before any participation. The tumors were graded and categorized according to the sixth edition of the American Joint Committee on Cancer, Cancer Staging Manual. ${ }^{33}$ At least 12 lymph nodes were examined in each patient except four patients in which the numbers of lymph nodes examined were fewer than 12 because of the inadequate lymph node recovery after surgical operation. Baseline characteristics of the patients are shown in Table 1. Probably because most people in Taiwan are un- willing to undergo early colorectal cancer screening, there was only one case of carcinoma in situ in these patients. Serum samples were collected by allowing blood to sit at room temperature for a minimum of 30 minutes to allow clots to form. To remove any possible suspended cells or cell debris in serum, samples were centrifuged at 10,000 rpm for 10 minutes, after which supernatants were harvested and stored at $-80^{\circ} \mathrm{C}$.

\section{Glutathione S-Transferase-CSE1L Fusion Protein Production and CSE1L Purification}

The glutathione S-transferase (GST)-CSE1L fusion protein expression vector was constructed by PCR amplification of the restriction enzyme-linearized pcDNA-CSE1L vector $^{28}$ with the primers $5^{\prime}$-GGATCCATGGAACTCAGCGATGCAAATCTG-3' (sense, BamH I site is italicized) and 5'-CTCGAGTTAAAGCAGTGTCACACTGGCTG-3' (antisense, Xho I site is italicized). The amplified products were subcloned into the BamH I and Xho I sites of the pGEX-4T-1 vector (Amersham Pharmacia) to obtain pGEX-CSE1L vector. The pGEX-CSE1L vector was transformed into the Escherichia coli Rosetta (DE3)/pLysS strain (Novagen, Madison, WI). The GST-CSE1L fusion protein was induced with $0.1 \mathrm{mmol} / \mathrm{L}$ of isopropyl- $\beta$-Dthiogalactopyranoside for 5 hours. GST-CSE1L fusion proteins were purified by glutathione-Sepharose 4B beads by using Bulk GST Purification Modules (Amersham Pharmacia) and cleaved with thrombin (3 units/100 $\mu \mathrm{g}$ of fusion protein) (Sigma Chemicals, St Louis, MO) at $22^{\circ} \mathrm{C}$ for 16 hours. Thrombin and GST were removed by using Amicon Ultra-4 Centrifugal Filter Units (Millipore, Billerica, MA). Purified CSE1L protein was identified by immunoblotting with anti-CSE1L antibodies, and protein concentration was determined with a bicinchoninic acid protein assay kit (Pierce, Rockford, IL).

\section{Enzyme-Linked Immunosorbent Assay}

Anti-CSE1L (C-20) antibody-coated 96-well plates (Costar, Cambridge, MA) were blocked with 5\% bovine serum albumin in PBS for 1 hour. Wells were washed with PBS and then incubated with serum samples (threefold diluted with PBS containing $1 \%$ bovine serum albumin) for 2 hours. After washing with $0.05 \%$ Tween 20 in PBS, wells were incubated with biotin-conjugated rabbit anti-CSE1L antibodies for 1.5 hours. Biotin-conjugated rabbit antiCSE1L antibodies were prepared by biotinylating rabbit anti-CSE1L antibodies (AP1935a) by using the Biotin Labeling Kit-NH2 according to the manufacturer's protocol (Dojindo Laboratories, Kumamoto, Japan). Wells were washed with $0.05 \%$ Tween 20 in PBS and then reacted with streptavidin-conjugated horseradish peroxidase ( $R$ and D Systems, Minneapolis, MN), followed by incubation with substrate reagent ( $R$ and $D$ Systems). The reaction was stopped by sulfuric acid. For calibration, four blank wells containing PBS were used to determine background value. Eight wells that were not coated with antiCSE1L antibodies but did react with all other enzymelinked immunosorbent assay reagents were used as the 
Table 1. Baseline Characteristics of the Patients with Colorectal Cancer

\begin{tabular}{|c|c|c|c|c|}
\hline $\begin{array}{l}\text { Clinicopathological } \\
\text { parameter }\end{array}$ & Stage I $(n=25)$ & Stage $\|(n=26)$ & Stage III $(n=42)$ & Stage IV $(n=9)$ \\
\hline Mean age, range, $\mathrm{yr}^{\dagger}$ & $61.2 \pm 12.9,29-83$ & $67.0 \pm 13.2,36-91$ & $63.8 \pm 14.7,26-86$ & $67.8 \pm 15.7,45-89$ \\
\hline \multicolumn{5}{|l|}{ Sex } \\
\hline Male & 10 & 13 & 16 & 4 \\
\hline Female & 15 & 13 & 26 & 5 \\
\hline \multicolumn{5}{|l|}{ Primary site } \\
\hline Cecum & 3 & 1 & 1 & 0 \\
\hline Rectum & 7 & 8 & 16 & 3 \\
\hline Sigmoid colon & 11 & 6 & 6 & 2 \\
\hline Colon & 2 & 3 & 9 & 1 \\
\hline Transverse colon & 0 & 0 & 2 & 0 \\
\hline Hepatic flexure of colon & 0 & 0 & 0 & 1 \\
\hline Splenic flexure of colon & 0 & 1 & 0 & 0 \\
\hline Rectosigmoid junction & 1 & 2 & 1 & 0 \\
\hline Descending colon & 0 & 3 & 2 & 2 \\
\hline Ascending colon & 1 & 2 & 4 & 0 \\
\hline Appendix & 0 & 0 & 1 & 0 \\
\hline \multicolumn{5}{|l|}{ Primary tumor $(T)^{\ddagger}$} \\
\hline $\mathrm{T} 1$ & 4 & 0 & 1 & 0 \\
\hline T2 & 21 & 0 & 3 & 0 \\
\hline T3 & 0 & 26 & 34 & 7 \\
\hline $\mathrm{T} 4$ & 0 & 0 & 4 & 2 \\
\hline \multicolumn{5}{|l|}{$\begin{array}{l}\text { Lymph node }(\mathrm{N})^{\S} \text { and } \\
\quad \text { distant metastasis }(\mathrm{M})^{\uparrow}\end{array}$} \\
\hline NOMO & 25 & 26 & 0 & 0 \\
\hline N1M0 & 0 & 0 & 24 & 0 \\
\hline N2MO & 0 & 0 & 18 & 0 \\
\hline NOM1 & 0 & 0 & 0 & 2 \\
\hline N1M1 & 0 & 0 & 0 & 2 \\
\hline $\mathrm{N} 2 \mathrm{M} 1$ & 0 & 0 & 0 & 5 \\
\hline
\end{tabular}

${ }^{*}$ A patient with carcinoma in situ is not included

tData presented as mean \pm SD

¥T1: invades to submucosa; T2: invades to muscle layers; T3: invades to pericolic tissues; T4: invades to other organs.

§N0: no regional lymph node metastasis; N1: metastasis in 1-3 regional lymph nodes; N2: metastasis in $\geq 4$ regional lymph nodes; M0: no distant metastasis; M1: distant metastasis.

"All of these M1 cases were distant metastases of colorectal tumors to the liver.

negative control wells. Absorbance at $450 \mathrm{~nm}$ was measured within 30 minutes with a Thermo Multiskan EX Microplate Photometer (Thermo Fisher Scientific, Waltham, MA). The optical density value of the sample well that was higher than 2 SDs above the mean of the optical density value of the negative control wells was considered to be positive for serum CSE1L. Each sample was assayed two times and the results were very similar, indicating the accuracy of the assay.

\section{Serum CEA Assay}

CEA values of patient samples were measured by using the Architect CEA Reagent kit (Abbott Laboratories, Abbott Park, IL) in accordance with the manufacturer's instructions. According to the manufacturer's instructions, a CEA value of $\geq 5 \mathrm{ng} / \mathrm{ml}$ was considered pathologically positive.

\section{Animal Metastasis Experiment}

A total of 66 mice (C57BL/6 mice; age range, 6 to 7 weeks old; National Laboratory Animal Center, Taipei, Taiwan) were housed under standard conditions $\left(22^{\circ} \mathrm{C}\right.$; $50 \%$ humidity; 12 -hour light/dark cycle). The animal metastasis experiment included three groups, and each experimental group included 11 mice injected with B16-EV cells and 11 mice injected with B16-antiCSE1L cells. Each mouse was injected in the tail vein with viable B16-EV cells or B16-anti-CSE1L cells $\left(5 \times 10^{4}\right.$ cells in $50 \mu \mathrm{l}$ of Dulbecco's modified Eagle's medium/ mouse). Twenty-five days after injection, mice were sacrificed and necropsied. Tumors in the colorectal tract and lungs were counted by macrography and micrography. Mouse care and experimental procedures were performed following the guideline of the Animal Care Committee of Academia Sinica, Taiwan.

\section{Statistical Analysis}

Data were analyzed by using SPSS 14.0 statistical software (SPSS, Chicago, IL). Statistical differences were analyzed by two-tailed Fisher's exact test or paired $t$-test. An $\alpha$ level of 0.05 was used to determine statistical significance.

\section{Results}

\section{Vesicle-Like Staining of CSE1L in the Protrusions of HT-29 Colorectal Cancer Cells}

We studied the cellular distribution of CSE1L in HT-29 colorectal cancer cells by immunofluorescence. CSE1L 


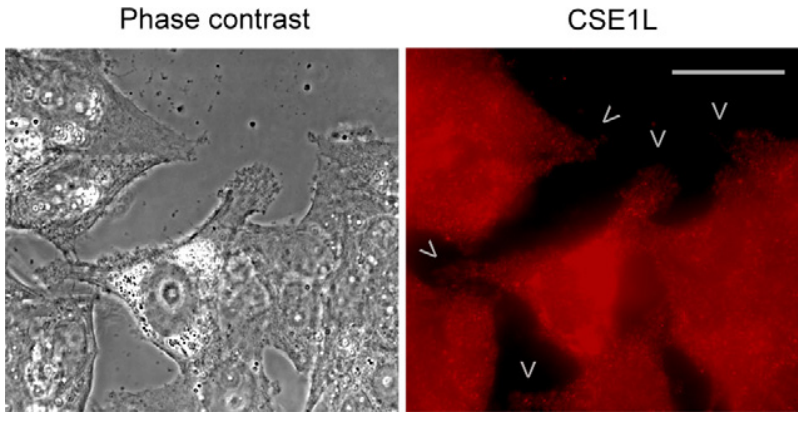

Figure 1. Vesicle-like staining of CSE1L in HT-29 colorectal cancer cells. The cellular distribution of CSE1L in HT-29 cells was analyzed by immunofluorescence with clone 24 anti-CSE1L antibodies. Note that in addition to granule-like staining in the perinuclear areas, vesicle-like staining was observed in the cytoplasm near the cell membrane and in cell protrusions (arrowheads). Scale bar $=10 \mu \mathrm{m}$

is known to associate with importin- $\alpha,{ }^{34}$ a nuclear-transport receptor, and microtubules. ${ }^{19}$ Therefore, CSE1L should show granule-like staining in the perinuclear areas of cells because of its association with importin- $\alpha$ or show microtubule-like staining because of its association with microtubules. However, in addition to granule-like staining in the cytoplasm surrounding perinuclear areas, CSE1L also showed vesicle-like staining in the protrusions of HT-29 cells (Figure 1). Cytoplasmic vesicles are vehicles of cell secretion. ${ }^{35}$ Therefore, CSE1L may play a role in regulating the secretion of colorectal cells.

\section{CSE1L in Gland Lumen of Colorectal Cancer and Sera of Patients with Metastatic Colorectal \\ Cancer}

The distribution of CSE1L in human colorectal cancer tissue was studied by immunohistochemistry. MMP-2 is a secretory protein, and the control assay stained positively for MMP-2 in both stroma and gland lumen of cancer samples (Figure 2, A and B). Immunohistochemistry with clone 3D8 anti-CSE1L antibodies showed that CSE1L was mainly distributed in the cytoplasm of cells in tumor glands (Figure 2, C-F). Positive staining for CSE1L was observed in the stroma of tissue taken from metastatic lesions (Figure 2C). Importantly, positive staining of CSE1L was also observed in the gland lumen of metastatic lesions (Figure 2, D-F). Substances secreted from a gland lumen can ultimately reach blood vessels. ${ }^{36}$ CSE1L staining in the gland lumen of metastatic cancer tissues indicated that CSE1L was secreted into the lumen of glands within metastatic tissues.

The presence of serum CSE1L in patients with metastatic colorectal cancer was studied by immunoblotting with anti-CSE1L antibodies. CSE1L was shown to be present in conditioned medium harvested from serumstarved B16-F10 cells, a highly metastatic cancer cell line (Figure 3, lane 2), confirming that CSE1L is a secretory protein. The results of immunoblotting with sera obtained from patients with metastatic colorectal cancer showed clear CSE1L protein bands in the immunoblot (Figure 3, lanes 3 to 13), indicating that CSE1L was present in the sera of patients with metastatic colorectal cancer.

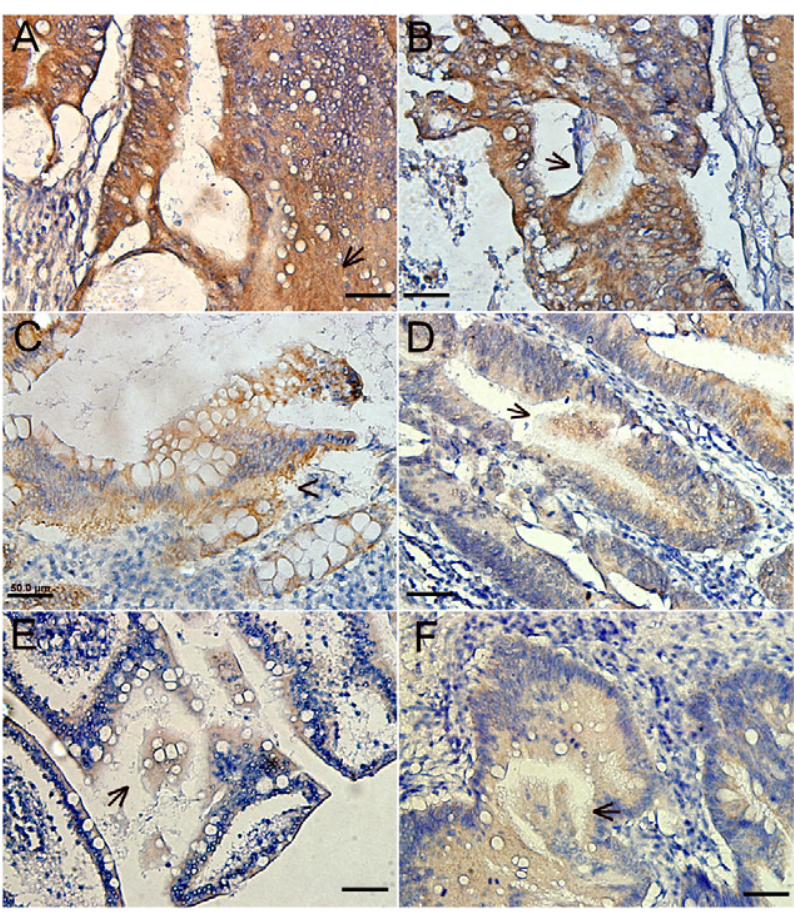

Figure 2. CSE1L staining in the gland lumen of colorectal cancer tissue Distribution of CSE1L in metastatic colorectal cancer tissue was analyzed by immunohistochemistry with clone 3D8 anti-CSE1L antibodies. CSE1L staining was seen in the stroma (C, arrowhead) and gland lumen (D-F, arrows) of tissues. MMP-2 is a secretory protein, and its distribution was analyzed as the control. Positive staining for MMP-2 was also observed in the stroma (A arrowhead) and gland lumen (B, arrows) of colorectal cancer tissue. Note the heavy staining of MMP-2 and CSE1L in large and cloud-like clumps in the gland lumen. Scale bars $=50 \mu \mathrm{m}$.

\section{CSE1L Is Superior to CEA in Diagnosis of Metastatic Colorectal Cancer}

The competency of serum CSE1L and CEA in diagnosis of metastatic colorectal cancer was studied by using enzyme-linked immunosorbent assay. The positive rate for measurable serum CSE1L in healthy donors was $8.5 \%$

Sera from metastastic colorectal cancer patients
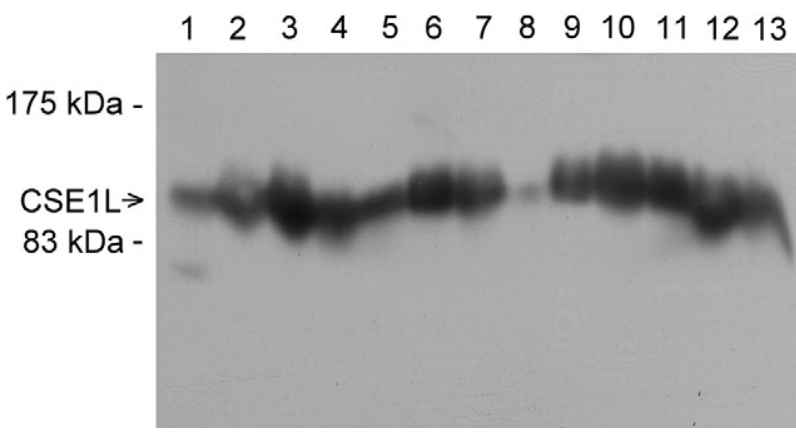

Figure 3. CSE1L protein in sera of patients with metastatic colorectal cancer. The presences of secretory CSE1L in serum of patients with metastatic colorectal cancer were evaluated by immunoblotting with anti-CSE1L antibodies. Wells loaded with the B16-F10 total cell lysate (lane 1) and conditioned medium collected from serum-starved B16-F10 cells (lane 2) were used as controls. Each well was loaded with $15 \mu \mathrm{l}$ of serum sample or with $50 \mu \mathrm{l}$ of conditioned medium collected from serum-starved B16-F10 cells. Note the sharp and intense CSE1L protein bands in wells loaded with sera from patients with metastatic colorectal cancer. 
Table 2. A Comparison of Serum CSE1L and CEA in Colorectal Cancer Diagnosis

\begin{tabular}{lccccc}
\hline \multicolumn{1}{c}{ Groups } & $\begin{array}{c}\text { Healthy donor } \\
(n=47)\end{array}$ & $\begin{array}{c}\text { Stage I } \\
(n=25)\end{array}$ & $\begin{array}{c}\text { Stage II } \\
(n=26)\end{array}$ & $\begin{array}{c}\text { Stage III } \\
(n=42)\end{array}$ & $\begin{array}{c}\text { Stage IV } \\
(n=9)\end{array}$ \\
\hline CSE1L-positive, cases (\%) & $4(8.5)$ & $9(36.0)^{\star}$ & $15(57.7)^{\ddagger}$ & $30(71.4)^{\natural}$ & $8(88.9)^{\star *}$ \\
CEA-positive, cases (\%) & Not assayed & $4(16.0)$ & $11(42.3)$ & $20(47.6)$ & $7(77.8)$ \\
CSE1L or CEA-positive, cases (\%) & Not assayed & $12(48.0)^{\dagger}$ & $17(65.4)^{\S}$ & $37(88.1)^{\|}$ & $9(100)^{\dagger+}$ \\
\hline
\end{tabular}

${ }^{*} P=0.021$, compared with that of CEA-positive cases in stage I group.

${ }^{\dagger} P=0.0025$, compared with that of CEA-positive cases in stage I group.

$\ddagger P=0.043$, compared with that of CEA-positive cases in stage II group.

$\$ P=0.011$, compared with that of CEA-positive cases in stage II group.

"P $P=0.0009$, compared with that of CEA-positive cases in stage III group.

$\| P=0.000004$, compared with that of CEA-positive cases in stage III group.

${ }^{* *} P=0.346$, compared with that of CEA-positive cases in stage IV group.

${ }^{+\top} P=0.169$, compared with that of CEA-positive cases in stage IV group.

(4 of 47; Table 2). Among 103 patients with cancer, serum CSE1L was detected in 36.0\% (9 of 25) of patients with stage I disease, and a pathological serum CEA level was found in $16.0 \%$ ( 4 of 25 ) of the same patients $(P=$ $0.021)$; the positive rate was $48.0 \%$ (12 of 25) for a combined CSE1L/CEA assay ( $P=0.0025$, compared with the rate for detection with only CEA; Table 2). For patients with stage II disease, serum CSE1L was detected in $57.7 \%$ (15 of 26) of patients compared with a pathological serum level of CEA in $42.3 \%$ (11 of 26) of the same patients $(P=0.043)$; the positive rate was $65.4 \%$ (17 of 26) for a combined CSE1L/CEA assay $(P=0.011$, compared with the rate for assay by only CEA; Table 2 ). For patients with stage III disease, serum CSE1L was detected in $72.1 \%$ (30 of 42 ) of patients, whereas a pathological serum level of CEA was found in $48.8 \%$ (20 of 42 ) of the same patients ( $P=0.0009)$; the positive rate was $88.1 \%$ (37 of 42) for a combined CSE1L/CEA assay $(P=0.000004$, compared with the rate for CEA assay only; Table 2). For patients with stage IV disease, serum CSE1L was detected in $88.9 \%$ (8 of 9) of patients, whereas a pathological serum level of CEA was found in $77.8 \%$ (7 of 9 ) of the same patients $(P=0.346)$; the positive rate was $100 \%$ (9 of 9 ) for a combined CSE1L/ CEA assay $(P=0.169$, compared with the rate for CEA assay only; Table 2). The cut-off value of CSE1L in the sera of patients with colorectal cancer was determined to be $\geq 6 \mathrm{ng} / \mathrm{ml}$ with the use of purified CSE1L protein as a standard. Assay for serum CSE1L significantly increased the sensitivity of staging colorectal cancer compared with staging done solely with assay for serum CEA (Table 2). In addition, the combined serum CSE1L/CEA assay further increased sensitivity (Table 2). The relative levels of CSE1L and CEA associated with the colorectal cancer stages are shown in Figure 4.

Because lymphatic metastasis is an important indicator of poor prognosis for patients with colorectal cancer, a cancer marker that can reliably diagnose lymphatic metastasis would be clinically important. Serum CSE1L was detected in $74.5 \%$ (38 of 51) of patients with metastatic colorectal cancer (eg, stage III and IV cancers), whereas a pathological level of CEA was found in only $52.9 \%$ (27 of 51) of these patients $(P=0.0005$; Table 3 ). The combined CSE1L/CEA assay identified $90.2 \%$ (46 of 51) of patients with metastatic colorectal cancer $(P<$ 0.0001 , compared with the rate for assay by CEA only;
Table 3). The sensitivity and specificity of CSE1L for detection of colorectal cancer were $60.8 \%$ and $91.5 \%$, respectively. The sensitivity and specificity of CSE1L for detection of metastatic colorectal cancer were $74.5 \%$ and $52.9 \%$, respectively. Because there might be a significant fraction of stage I and stage II patients who are understaged by current diagnostic methods, the values might be better. The sensitivity and specificity of CEA for detection of metastatic colorectal cancer were 52.9\% and $70.6 \%$, respectively. The sensitivity and specificity of combined CSE1L/CEA assay for detection of metastatic colorectal cancer were $90.2 \%$ and $43.1 \%$, respectively.

\section{Reduced CSE1L Expression Decreased Metastasis of B16-F10 Cells to the Colorectal Tract in C57BL/6 Mice}

It has been reported that malignant melanoma is a frequent source of metastasis to the gastrointestinal tract, including the colon. ${ }^{37} \mathrm{C} 57 \mathrm{BL} / 6 \mathrm{~J}$ mice injected intravenously via the tail vein with B16 melanoma cells
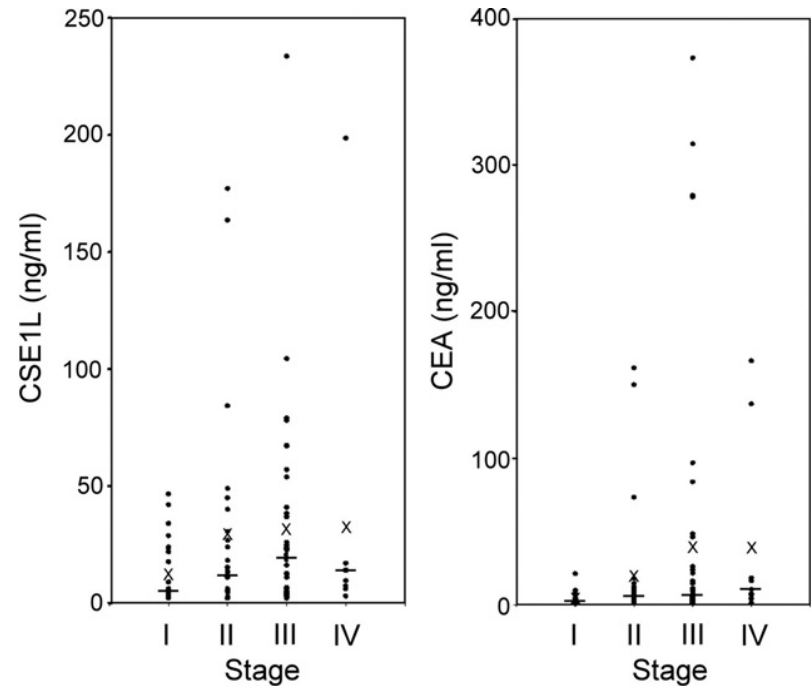

Figure 4. The relative levels of CSE1L and CEA associated with the colorectal cancer stages. The concentrations of CSE1L and CEA in sera from patients with colorectal cancer were measured by enzyme-linked immunosorbent assay and a CEA detection kit, and are shown by dot-plots as indicated. The line in each stage indicates the median value of the data, and a cross indicates the mean value of the data. 
Table 3. The Sensitivity of Lymphatic Metastasis of Colorectal Cancer Assayed by CSE1L and CEA

\begin{tabular}{cccc}
\hline Groups & $\begin{array}{c}\text { Lymph node } \\
\text { metastasis } \\
(n=42)^{\star}\end{array}$ & $\begin{array}{c}\text { Distant } \\
\text { metastasis } \\
(n=9)^{\dagger}\end{array}$ & $\begin{array}{c}\text { Lymph node } \\
\text { or distant } \\
\text { metastasis } \\
(n=51)\end{array}$ \\
\hline $\begin{array}{c}\text { CSE1L-positive, } \\
\text { cases (\%) }\end{array}$ & $30(71.4)^{\ddagger}$ & $8(88.9)^{\Uparrow}$ & $38(74.5)^{\star \star}$ \\
$\begin{array}{c}\text { CEA-positive, } \\
\text { cases (\%) }\end{array}$ & $20(47.6)$ & $7(77.8)$ & $27(52.9)$ \\
$\begin{array}{c}\text { CSE1L or } \\
\text { CEA-positive, } \\
\text { cases (\%) }\end{array}$ & $37(88.1)^{\S}$ & $9(100)^{\|}$ & $46(90.2)^{\dagger \dagger}$ \\
\hline
\end{tabular}

*Lymph node metastasis: NOMO, N1MO, and N2MO

+Distant metastasis: NOM1, N1M1, and N2M1.

$\neq P=0.0009$, compared with that of CEA-positive cases in the lymphatic metastasis group.

$\$ p=0.000004$, compared with that of CEA-positive cases in the lymphatic metastasis group.

${ }^{\mathbb{P}} P=0.346$, compared with that of CEA-positive cases in the distant metastasis group.

$\| P=0.169$, compared with that of CEA-positive cases in the distant metastasis group

${ }^{*} P=0.0005$, compared with that of CEA-positive cases in the lymph node or distant metastasis group.

${ }^{+T} P<0.0001$, compared with that of CEA-positive cases in the lymph node or distant metastasis group.

have been shown to grow colorectal tumors. ${ }^{32,38}$ We studied the effect of reduced CSE1L expression on metastasis of B16-F10 cells, a highly metastatic cancer cell line, to the colorectal tract of C57BL/6 mice. Western blotting showed that B16-F10 cells transfected with pcDNA-anti-CSE1L vectors (eg, B16-anti-CSE1L cells) had decreased expression of CSE1L compared with expression in B16-F10 cells and B16-EV cells, the latter the empty pcDNA3.1 vector-transfected B16-F10 cells (Figure $5 \mathrm{~A})$. C57BL/6 mice were injected in the tail vein with viable B16-EV cells or B16-anti-CSE1L cells. Tumors were examined and counted 25 days after injection. The lungs are the primary metastatic site for B16-F10 cells in C57BL/6 mice. Our data showed that reduced CSE1L expression decreased pulmonary metastasis of B16-F10 cells by $56 \%(P=0.0107)$. The average number of pulmonary tumors in mice injected with B16-anti-CSE1L cells was $14.3 \pm 4.6$ tumors per mouse (mean \pm SE; average tumor diameter, $2.5 \pm 1.5 \mathrm{~mm}$ ) compared with $32.7 \pm 6.5$ tumors per mouse (mean $\pm \mathrm{SE}$; average tumor diameter, $2.6 \pm 1.8 \mathrm{~mm}$ ) for mice injected with B16-EV cells. In addition to metastasizing to the lungs, many C57BL/6 mice injected with B16-EV cells showed metastasis of tumor cells to the colorectal tract (Figure 5B). Significantly, mice injected with B16-EV cells showed higher numbers of tumors in the colorectal tract than mice injected with B16-anti-CSE1L cells. The average number of colorectal tumors in mice injected with B16-EV cells was $0.79 \pm 0.19$ tumors per mouse (mean \pm SE; average tumor diameter, $6.6 \pm 3.4 \mathrm{~mm}$ ), whereas it was $0.33 \pm$ 0.11 tumors per mouse (mean \pm SE; average tumor diameter, $3.5 \pm 1.9 \mathrm{~mm}$ ) for mice injected with B16-antiCSE1L cells ( $P=0.041$; Figure $5 \mathrm{~B})$. The results indicate that CSE1L plays a major role in regulating metastasis of cancers in the colorectal tract. In the animal metastasis studies, 11 B16-EV cell-injected mice and six B16-antiCSE1L cell-injected mice died 3 weeks after injection $(P=0.022 ;$ Figure 5C). Anti-CSE1L transfection reduced mortality of mice injected with B16-F10 cells.

\section{Discussion}

Cancer cells that develop an enhanced ability to secrete extracellular matrix-degradation proteinases become more likely to metastasize. CSE $1 \mathrm{~L}$ is located on chromosome 20q13; this chromosome region is frequently amplified in colorectal cancer, and amplification correlates
A
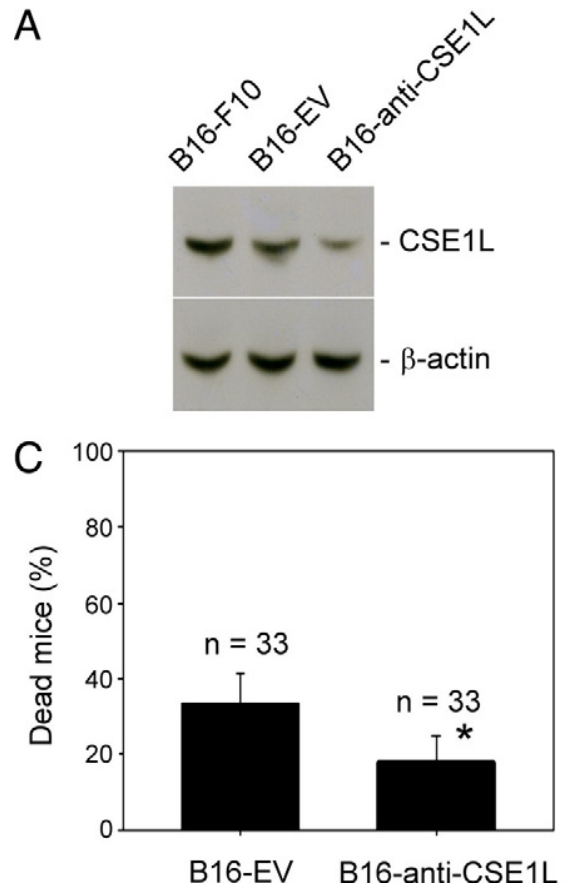

B
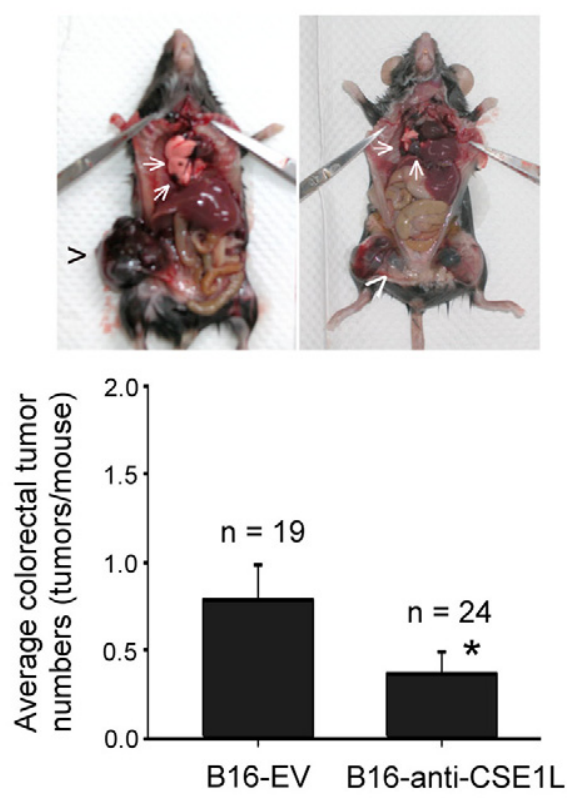

Figure 5. Reduced CSE1L expression correlated with decreased metastasis of B16-F10 cells to the colorectal tract in $\mathrm{C} 57 \mathrm{BL} / 6$ mice. A: Expression levels of CSE1L in B16-EV and B16-anti-CSE1L cells were analyzed by immunoblotting with anti-CSE1L antibodies. Levels of $\beta$-actin were assayed with anti- $\beta$-actin antibodies as the control B: Reduced CSE1L expression correlated with decreased tumor cell metastasis to the colorectal tract. ${ }^{*} P=0.041$ compared with the number of metastases for mice injected with B16-EV control cells. The upper photograph is representative of tumors in the colorectal tract (arrowheads) and lungs (arrows). C: Reduced CSE1L expression decreased mortality of $\mathrm{C} 57 \mathrm{BL} / 6$ mice injected with B16-F10 cells. ${ }^{*} P=0.022$ compared with mortality of mice injected with B16-EV cells. There were three experimental groups, with each group including 11 mice injected with B16-EV cells and 11 mice injected with B16-antiCSE1L cells. A total of 66 mice were used. Metastatic tumors in the colorectal tract were counted 25 days after injection. Eleven mice injected with B16-EV cells and six mice injected with B16-anti-CSE1L cells died 3 weeks after injection. Six mice (three injected with B16-EV cells and three injected with B16-anti-CSE1L cells) did not develop tumors. These mice, as well as the mice that died 3 weeks after injection, were excluded from calculations of tumor metastasis. 
with greater biological aggression of the disease, particularly in patients found to have lymphatic or liver metastasis. ${ }^{29,30}$ Cytoplasmic vesicles play an important role in regulating secretion by cells. Our data showed vesiclelike staining of CSE1L in the cytoplasm as well as the protrusions of HT-29 colorectal cancer cells (Figure 1), suggesting CSE1L may play a role in secretion by colorectal cancer cells. Glands are the major epithelial components of tubular organs that mediate passage and control homeostasis by modifying secretion. Our immunohistochemistry study showed CSE1L staining in the cytoplasm of cells in tumor glands, stroma, and the gland lumen of metastatic colorectal cancer lesions (Figure 2). The results of Western blotting also showed that CSE1L was detected in sera of patients with metastatic colorectal cancer (Figure 3). Moreover, enzyme-linked immunosorbent assay showed a high prevalence of detectable CSE1L in sera of patients with metastatic colorectal cancer (Tables 2 and 3). The expression of CSE1L protein in cancer tissue has a positive correlation with high cancer stage and high cancer grade as well as worse clinical outcome of cancers including colorectal cancer, ${ }^{39}$ and this was thought to be related to stimulation of cancer cell proliferation by CSE1L. ${ }^{23}$ Our recent study revealed that CSE1L is unable to stimulate proliferation of cancer cells. ${ }^{27}$ Our present data suggest that CSE1L may play an important role in regulating secretion by colorectal cells and that CSE1L itself is a secretory protein associated with colorectal cancer metastasis. These findings define a new role for CSE1L in facilitating colorectal cancer progression and show that it may be useful for diagnosis and treatment of metastatic colorectal cancer.

Resection of tumor with adequate margins and associated mesentery including lymph nodes remains the primary treatment of colorectal cancer. Patients with lymphatic metastasis-positive disease (eg, stage III or stage IV cancer) may also benefit from adjuvant chemotherapy. ${ }^{40-43}$ Treating all patients with adjuvant chemotherapy is not recommended because of side effects in other tissues as well as the morbidity and mortality of unnecessary adjuvant chemotherapy. Metastasis of colorectal cancer to regional lymph nodes through lymphatic vessels is an important indicator of poor prognosis for patients with colorectal cancer. ${ }^{44}$ In an animal metastasis model, orthotopic microinjection of human colorectal cancer cells in nude mice induced a high degree of mesenteric and retroperitoneal lymphatic tumor foci (57\% to $100 \%)$, with tumor staging closely correlated to survival. ${ }^{45}$ Therefore, identification of lymph node metastases influences staging and subsequent therapy, making it one critical factor for making therapeutic decisions. ${ }^{46}$ Adjuvant chemotherapy is the standard treatment for stage III disease, but the benefit of adjuvant treatment in patients with stage II disease remains controversial. ${ }^{47}$ Although stage I and stage I| colorectal cancers are lymphatic metastasis-negative diseases as assessed by traditional histopathology methods, approximately 20\% to $30 \%$ of stage II patients experience recurrence, and many stage I patients die of local or distant recurrence after curative resection. ${ }^{4}$ Thus, there might be a significant fraction of stage I and stage II patients who are understaged by current evaluations and, consequently, are undertreated. In addition, the current standard for pathological examination of regional lymph nodes in a surgical resection specimen is a minimum of 12 lymph nodes for adequate staging. ${ }^{46}$ However, because of factors such as patient condition, surgical operation method, and inadequate lymph node recovery and/or assessment, the number of lymph nodes examined may be not enough in some cases and this also affects cancer staging and subsequent therapy ${ }^{48}$ Because detection of serum CSE1L in patients with colorectal cancer has a close relationship to lymphatic metastasis (Tables 2 and 3), CSE1L may be a useful marker for diagnosis of lymphatic metastasis in patients with colorectal cancer, particularly patients in whom it was not possible to obtain adequate lymph nodes for examination. Patients staged with stage I or II disease who are positive for serum CSE1L may have occult metastases, in which case adjuvant chemotherapy may be recommended. Also, deficient numbers of lymph nodes analyzed in pathological examination is not uncommon, raising the possibility of missing a diagnosis of lymphatic metastasis. Thus if patients have an insufficient number of lymph nodes examined and are positive for serum CSE1L, adjuvant chemotherapy may be advisable.

The advantage of using a serological marker in evaluating patients with colorectal cancer or possible recurrence is its relative noninvasiveness. CEA is the most frequently used blood marker in these patients, yet it is poor in detecting invasive tumors or limited metastatic disease. Hundt et al ${ }^{12}$ conducted a systematic review of articles in which the authors reported blood markers for early detection of colorectal cancer. On the basis of a search of the PubMed database ending in June 2006, they identified 93 studies evaluating 70 different markers. The majority of these markers were in test evaluation and only a few were in use for early diagnosis of colorectal cancer. Another comprehensive review published in October of 2008 showed there were 23 serum markers in preclinical development including PSME3, NNMT, CRMP-2, HNP 1-3, MIF, M-CSF, M2-PK, Prolactin, CCSA-2, CCSA-3, CCSA-4, MMP-7, MMP-9, Laminin, SELDI (eg, apolipoprotein C1, C3a-desArg, $\alpha$-antitrypsin, and transferrin), and a five-serum-marker panel (eg, Spondin-2, DcR3, Trail-R2, Reg IV, and MIC 1). CEA and CA 19-9 are in clinical use. ${ }^{49}$ CA $19-9$ is less sensitive than CEA for diagnosis of colorectal cancer. ${ }^{50}$ TIMP- 1 is the only marker that is in clinical validation, but its sensitivity in colorectal cancer diagnosis is still controversial. ${ }^{51-53}$ All of these markers were mainly for use in detecting early colorectal cancer, not metastatic disease. Thus, CSE1L may prove to have unique utility in diagnosis of metastatic colorectal cancer.

Our data showed that although CEA was less sensitive for lymphatic metastasis, a combined CSE1L/CEA assay significantly increased sensitivity (Tables 2 and 3). The combined serum CSE1L/CEA assay detected 88.1\% (37 of 42 ) of cases with lymphatic metastasis and $100 \%$ (9 of 9) of cases with distant metastasis (Table 3). The sensitivity for detection of lymph node or distant metastasis reached $90.2 \%$ (46 of 51 ) for the combined CSE1L/CEA 
assay (Table 3). Because of the apparent effectiveness of the CSE1L/CEA combination, further research is merited to determine what role it could play in the diagnosis of metastatic colorectal cancer.

Metastasis is the main characteristic of high-stage colorectal cancer and is also the main cause of colorectal cancer-related mortality. Because expression of CSE1L protein in colorectal cancer lesion has a positive correlation with advanced stage of cancer and worse clinical outcome, ${ }^{39}$ CSE1L may play a role in regulating metastasis of colorectal cancer and consequently worsening mortality. Our animal metastasis experiment showed that mice injected with B16-anti-CSE1L cells had reduced metastasis of tumor cells to the lungs and colorectal tract compared with metastasis for mice injected with the control vector-transfected B16-F10 cells (eg, B16-EV cells; Figure 5). Mice injected with B16-anti-CSE1L cells also showed reduced mortality compared with mortality for mice injected with B16-EV cells (Figure 5). Metastases are the main cause of cancer-related mortality, and so it is reasonable that mice injected with B16-anti-CSE1L cells had reduced metastasis rates and reduced mortality. These results confirm that CSE1L plays a role in regulating cancer metastasis and that it is related to patient mortality.

Colorectal cancers are known for high recurrence potential and for metachronous neoplasms in the colon or rectum. It is of the utmost importance to develop molecular markers that can predict which patients are at high risk for recurrence as a step toward more personalized decision-making regarding postresection treatment. Our data showed a high prevalence of serum CSE1L detection in patients with metastatic colorectal cancer, notably those with lymph node metastasis (Tables 2 and 3). Hence, preoperative and postoperative assay for serum CSE1L may facilitate identification of cases of lymphatic metastasis that are currently undetectable. Taking all of these findings together, CSE1L may be a novel marker that can improve the diagnostic workup of colorectal cancer, particularly of patients with colorectal cancer that has spread to the lymph nodes. In addition, CSE1L may be a potential target for therapeutic interventions in colorectal cancer.

\section{Acknowledgments}

We thank Sin-Lin Sin and Ya-Hui Chen for assistance with immunohistochemistry. We also thank Shu-Hui Lin for statistical analysis.

\section{References}

1. Andre N, Schmiegel W: Chemoradiotherapy for colorectal cancer. Gut 2005, 54:1194-1202

2. Lurje G, Zhang W, Lenz HJ: Molecular prognostic markers in locally advanced colon cancer. Clin Colorectal Cancer 2007, 6:683-690

3. Gill S, Loprinzi CL, Sargent DJ, Thomé SD, Alberts SR, Haller DG, Benedetti J, Francini G, Shepherd LE, Francois Seitz J, Labianca R, Chen W, Cha SS, Heldebrant MP, Goldberg RM: Pooled analysis of fluorouracil-based adjuvant therapy for stage II and III colon cancer: who benefits and by how much? J Clin Oncol 2004, 22:1797-1806
4. Carlson MR: Previstage GCC colorectal cancer staging test: a new molecular test to identify lymph node metastases and provide more accurate information about the stage of patients with colorectal cancer. Mol Diagn Ther 2009, 13:11-14

5. Losi L, Ponti G, Gregorio CD, Marino M, Rossi G, Pedroni M, Benatti $P$, Roncucci L, de Leon MP: Prognostic significance of histological features and biological parameters in stage I ( $\mathrm{pT} 1$ and pT2) colorectal adenocarcinoma. Pathol Res Pract 2006, 202:663-670

6. Di Gregorio C, Benatti P, Losi L, Roncucci L, Rossi G, Ponti G, Marino M, Pedroni M, Scarselli A, Roncari B, de Leon MP: Incidence and survival of patients with Dukes'A (stage T1 and T2) colorectal carcinoma: a 15-year population-based study. Int $\mathrm{J}$ Colorectal Dis 2005, 20:147-154

7. Booth RA: Minimally invasive biomarkers for detection and staging of colorectal cancer. Cancer Lett 2007, 249:87-96

8. Provenzale D, Gray RN: Colorectal cancer screening and treatment review of outcomes research. J Natl Cancer Inst Monogr 2004, 33:45-55

9. Gupta AK, Brenner DE, Turgeon DK: Early detection of colon cancer: new tests on the horizon. Mol Diagn Ther 2008, 12:77-85

10. Stein U, Schlag PM: Clinical, biological, and molecular aspects of metastasis in colorectal cancer. Recent Results Cancer Res 2007, 176:61-80

11. Huerta S: Recent advances in the molecular diagnosis and prognosis of colorectal cancer. Expert Rev Mol Diagn 2008, 8:277-288

12. Hundt $\mathrm{S}$, Haug $\mathrm{U}$, Brenner $\mathrm{H}$ : Blood markers for early detection of colorectal cancer: a systematic review. Cancer Epidemiol Biomarkers Prev 2007, 16:1935-1953

13. Tejpar S: The multidisciplinary management of gastrointestinal cancer. The use of molecular markers in the diagnosis and treatment of colorectal cancer. Best Pract Res Clin Gastroenterol 2007, 21:1071-1087

14. Thomson DM, Krupey J, Freedman SO, Gold P: The radioimmunoassay of circulating carcinoembryonic antigen of the human digestive system. Proc Natl Acad Sci USA 1969, 64:161-167

15. Moertel CG, Fleming TR, Macdonald JS, Haller DG, Laurie JA, Tangen C: An evaluation of the carcinoembryonic antigen (CEA) test for monitoring patients with resected colon cancer. JAMA 1993, 270:943-947

16. Fong S, García Vega G, León V: Carcinoembryonic antigen fraction in digestive cancer. Neoplasma 1985, 32:199-208

17. Sugarbaker PH: Role of carcinoembryonic antigen assay in the management of cancer. Adv Immun Cancer Ther 1985, 1:167-193

18. Chu DZ, Erickson CA, Russell MP, Thompson C, Lang NP, Broadwater RJ, Westbrook KC: Prognostic significance of carcinoembryonic antigen in colorectal carcinoma. Arch Surg 1991, 126:314-316

19. Brinkmann U, Brinkmann E, Gallo M, Pastan I: Cloning and characterization of a cellular apoptosis susceptibility gene, the human homologue to the yeast chromosome segregation gene CSE1. Proc Natl Acad Sci USA 1995, 92:10427-10431

20. Jiang MC, Luo SF, Li LT, Lin CC, Du SY, Lin CY, Hsu YW, Liao CF: Synergic CSE1L/CAS, TNFR-1, and p53 apoptotic pathways in combined interferon-gamma/adriamycin-induced apoptosis of Hep G2 hepatoma cells. J Exp Clin Cancer Res 2007, 26:91-99

21. Liao CF, Luo SF, Shen TY, Lin CH, Chien JT, Du SY, Jiang MC: CSE1L/CAS, a microtubule-associated protein, inhibits taxol (paclitaxel)-induced apoptosis but enhances cancer cell apoptosis induced by various chemotherapeutic drugs. BMB Rep 2008, 41:210-216

22. Liao CF, Luo SF, Tsai CS, Tsao TY, Chen SL, Jiang MC: CAS enhances chemotherapeutic drug-induced p53 accumulation and apoptosis: use of CAS for high-sensitivity anticancer drug screening Toxicol Mech Method 2008, 18:771-776

23. Behrens P, Brinkmann U, Wellmann A: CSE1L/CAS: its role in proliferation and apoptosis. Apoptosis 2003, 8:39-44

24. DeClerck YA, Mercurio AM, Stack MS, Chapman HA, Zutter MM, Muschel RJ, Raz A, Matrisian LM, Sloane BF, Noel A, Hendrix MJ, Coussens L, Padarathsingh M: Proteases, extracellular matrix, and cancer: a workshop of the path B study section. Am J Pathol 2004, 164:1131-1139

25. D'Andrea MR, Derian CK, Santulli RJ, Andrade-Gordon P: Differential expression of protease-activated receptors- 1 and -2 in stromal fibroblasts of normal, benign, and malignant human tissues. Am J Pathol 2001, 158:2031-2041

26. Emmert-Buck MR, Roth MJ, Zhuang Z, Campo E, Rozhin J, Sloane BF, Liotta LA, Stetler-Stevenson WG: Increased gelatinase A (MMP-2) 
and cathepsin B activity in invasive tumor regions of human colon cancer samples. Am J Pathol 1994, 145:1285-1290

27. Liao CF, Luo SF, Li LT, Lin CY, Chen YC, Jiang MC: CSE1L/CAS, the cellular apoptosis susceptibility protein, enhances invasion and metastasis but not proliferation of cancer cells. J Exp Clin Cancer Res 2008, 27:15

28. Tsao TY, Tsai CS, Tung JN, Chen SL, Yue CH, Liao CF, Wang CC, Jiang MC: Function of CSE1L/CAS in the secretion of HT-29 human colorectal cells and its expression in human colon. Mol Cell Biochem 2009, 327:163-170

29. Aust DE, Muders M, Köhler A, Schmidt M, Diebold J, Müller C, Löhrs $U$, Waldman FM, Baretton GB: Prognostic relevance of $20 q 13$ gains in sporadic colorectal cancers: a FISH analysis. Scand J Gastroenterol 2004, 39:766-772

30. Knösel T, Schlüns K, Stein U, Schwabe H, Schlag PM, Dietel M, Petersen I: Chromosomal alterations during lymphatic and liver metastasis formation of colorectal cancer. Neoplasia 2004, 6:23-28

31. Tung MC, Tsai CS, Tung JN, Tsao TY, Chen HC, Yeh KT, Liao CF, Jiang MC: Higher prevalence of secretory CSE1L/CAS in sera of patients with metastatic cancer. Cancer Epidemiol Biomarkers Prev 2009, 18:1570-1577

32. Tsai CS, Luo SF, Ning CC, Lin CL, Jiang MC, Liao CF: Acetylsalicylic acid regulates MMP-2 activity and inhibits colorectal invasion of murine B16F0 melanoma cells in C57BL/6J mice: effects of prostaglandin $\mathrm{F}_{2} \alpha$. Biomed Pharmacother 2009, 63:522-527

33. American Joint Committee on Cancer: AJCC Cancer Staging Manual. 6th ed. New York, Springer, 2002, pp 113-124

34. Kutay U, Bischoff FR, Kostka S, Kraft R, Gorlich D: Export of importin alpha from the nucleus is mediated by a specific nuclear transport factor. Cell 1997, 90:1061-1071

35. Pickett JA, Edwardson JM: Compound exocytosis: mechanisms and functional significance. Traffic 2006, 7:109-116

36. Pieper-Bigelow C, Strocchi A, Levitt MD: Where does serum amylase come from and where does it go? Gastroenterol Clin North Am 1990 19:793-810

37. Blecker D, Abraham S, Furth EE, Kochman ML: Melanoma in the gastrointestinal tract. Am J Gastroenterol 1999, 94:3427-3433

38. Wu X, Zeng H, Zhang X, Zhao Y, Sha H, Ge X, Zhang M, Gao X, Xu $Q$ : Phosphatase of regenerating liver-3 promotes motility and metastasis of mouse melanoma cells. Am J Pathol 2004, 164:2039-2054

39. Seiden-Long IM, Brown KR, Shih W, Wigle DA, Radulovich N, Jurisica I, Tsao MS: Transcriptional targets of hepatocyte growth factor signaling and Ki-ras oncogene activation in colorectal cancer. Oncogene 2006, 25:91-102

40. Nelson H, Petrelli N, Carlin A, Couture J, Fleshman J, Guillem J, Miedema B, Ota D, Sargent D; National Cancer Institute Expert Panel:
Guidelines 2000 for colon and rectal cancer surgery. J Natl Cancer Inst 2001, 93:583-596

41. Consensus NIH Conference: Adjuvant therapy for patients with colon and rectal cancer. JAMA 1990, 264:1444-1450

42. Moosmann N, Heinemann V: Cetuximab plus oxaliplatin-based chemotherapy in the treatment of colorectal cancer. Expert Rev Anticancer Ther 2008, 8:319-329

43. Kulig J, Popiela T, Richter P, Klek S: Evaluation of adjuvant chemotherapy irinotecan +5 -fluorouracil + leucovorine in advanced colorectal cancer. Acta Chir Belg 2007, 107:297-301

44. Omachi T, Kawai Y, Mizuno R, Nomiyama T, Miyagawa S, Ohhashi T, Nakayama J: Immunohistochemical demonstration of proliferating lymphatic vessels in colorectal carcinoma and its clinicopathological significance. Cancer Lett 2007, 246:167-172

45. Céspedes MV, Espina C, García-Cabezas MA, Trias M, Boluda A Gómez del Pulgar MT, Sancho FJ, Nistal M, Lacal JC, Mangues R: Orthotopic microinjection of human colon cancer cells in nude mice induces tumor foci in all clinically relevant metastatic sites. Am J Pathol 2007, 170:1077-1085

46. Lemmens VE, van Lijnschoten I, Janssen-Heijnen ML, Rutten HJ, Verheij CD, Coebergh JW: Pathology practice patterns affect lymph node evaluation and outcome of colon cancer: a population-based study. Ann Oncol 2006, 17:1803-1809

47. Demols A, Van Laethem JL: Adjuvant chemotherapy for colorectal cancer. Curr Gastroenterol Rep 2002, 4:420-426

48. Horzic M, Kopljar M: Minimal number of lymph nodes that need to be examined for adequate staging of colorectal cancer-factors influencing lymph node harvest. Hepatogastroenterology 2005, 52:86-89

49. Kim HJ, Yu MH, Kim H, Byun J, Lee C: Noninvasive molecular biomarkers for the detection of colorectal cancer. BMB Rep 2008, 41:685-692

50. Duffy MJ: CA 19-9 as a marker for gastrointestinal cancers: a review. Ann Clin Biochem 1998, 35:364-370

51. Oberg A, Höyhtyä M, Tavelin B, Stenling R, Lindmark G: Limited value of preoperative serum analyses of matrix metalloproteinases (MMP-2, MMP-9) and tissue inhibitors of matrix metalloproteinases (TIMP-1, TIMP-2) in colorectal cancer. Anticancer Res 2000, 20:1085-1091

52. Korotkova EA, Gershteĭn ES, Prorokov VV, Kushlinski i NE: Tissue inhibitor of metalloproteinase-1 (TIMP-1) in colorectal cancer: correlation with clinico-morphological factors. Vopr Onkol 2009, 55:171-176

53. Møller Sørensen N, Vejgaard Sørensen I, Ørnbjerg Würtz S, Schrohl AS, Dowell B, Davis G, Jarle Christensen I, Nielsen HJ, Brünner N Biology and potential clinical implications of tissue inhibitor of metalloproteinases-1 in colorectal cancer treatment. Scand J Gastroenterol 2008, 43:774-786 